УДК 811.161.1'42

ББК 81.055

DOI: https://doi.org/10.17308/lic.2020.4/3073

\title{
ОПЫТ ПОСТРОЕНИЯ ИСЧИСЛЯЮЩЕЙ КЛАССИФИКАЦИИ ИНТЕРТЕКСТОВЫХ ЕДИНИЦ
}

\author{
С. А. Чуриков \\ Воронежский государственный университет
}

\begin{abstract}
AN ATTEMPT AT CONSTRUCTING AN ENUMERATIVE CLASSIFICATION OF INTERTEXTUAL UNITS
\end{abstract}

\author{
S. A. Churikov \\ Voronezh State University
}

\begin{abstract}
Аннотация: в статье предпринята попытка построения исчисляющей классификации интертекстовых единиц. Придерживаясь «широкого» подхода к трактовке интертекстовых связей, автор считает, что интертекстовыми единицами являются любые элементы текста А или множества текстов В, а также целье тексты, которые были в том или ином виде заимствованы в текст C или множество текстов $D$. Так понимаемую интертекстовую единииу предлагается называть термином коннектема (от англ. conпесt - соединять(ся), связывать(ся), ассоичироваться), который создан по продуктивной для лингвистической терминологии модели (морфема, фонема и т. д.) и своей внутренней форме передает идею связи. В различных контекстах одна и та же коннектема может быть представлена в тех или иных своих разновидностях, которые автор предлагает называть коннектами. Важнейтей задачей интертекстолога должно стать системное описание коннектем как парадигм коннектов. Такое описание может быть получено, если будет построена исчисляющая классификация коннектов. С точки зрения автора, в ее основу должна быть положена следующая триада параметров: 1) атрибутированность/неатрибутированность; 2) маркированность/немаркированность; 3) каноничность/трансформированность. Применение этой классификации показывает, что парадигма интертекстовых единии, составляюших коннектему, представляет собой множество из восьми базовых вариантов во главе с основным вариантом четко атрибутированным, маркированным и каноническим коннектом. Остальные семь типов образуются в результате применения к основному варианту следующих операций: 1) снятия атрибуции; 2) снятия маркировки; 3) трансформации. Различные типы коннектов связаны с их реализаџией в определенных текстовых позициях. По мнению автора, сущзественное значение для функиионирования коннектов имеют три текстовые позиции: 1) эпиграф; 2) заглавие; 3) тело текста. При этом именно позиция эпиграфа, спещиально предназначенная для размещения интертекстовых единии, является сильной для коннектов, которые обычно сохраняют здесь все характеристики текста-источника, снабжаются четкой атрибуцией и особым образом маркируются. Предложенная исчисляющая классификация коннектов позволяет описать и «предсказать» любой вариант употребления коннектемы, что открывает широкие возможности ее применения.
\end{abstract}

Ключевые слова: интертекст, интертекстовая единица, интертекстовая терминология, исчисляющая классификация, текстовая позиция.

Abstract: the article attempts to construct an enumerative classification of intertextual units. Taking a «broad» approach to the interpretation of intertextual relations, the author suggests that intertextual units are any elements of text $A$ or a set of texts $B$, as well as whole texts that have been borrowed in one form or another into text $C$ or set of texts $D$. So the understood intertextual unit is proposed to be called the term connecteme, which is created according to the productive model for linguistic terminology (morpheme, phoneme, etc.) and conveys the idea of

(C) Чуриков С. А., 2020

Контент доступен под лицензией Creative Commons Attribution 4.0 License.

The content is available under Creative Commons Attribution 4.0 License. 
connection in its internal form. In different contexts, the same token can be represented in one or another of its varieties, which the author proposes to name connects. The most important task of the intertextologist should be the systematic description of connectemes as paradigms of connects. Such a description can be obtained if an enumerative classification of connects is constructed. From the author's point of view, it should be based on the following triad of parameters: 1) attribution/non-attribution; 2) marking/unmarked; 3) canonicity/transformability. The application of this classification shows that the paradigm of the intertext units that make up the connecteme includes a set of eight basic variants, led by the main variant - a clearly attributed, marked and canonical connect. The remaining seven types are formed by applying the following operations to the main variant: 1) de-attribution; 2) removal of marking; 3) transformations. Different types of lexes are associated with their implementation in certain text positions. According to the author, three text positions are essential for the functioning of connects: 1) epigraph; 2) title; 3) body of text. Moreover, it is the position of the epigraph, specially designed to accommodate intertext units, that is strong for connects, which are usually preserved here by all the characteristics of the source text, are provided with clear attribution and are specially marked. The proposed enumerative classification of lexes allows us to describe and "predict» any option for using lexes, which opens up wide possibilities for its use. Key words: intertext, intertextual unit, intertextual terminology, enumerative classification, text position.

\section{Введение}

«Хотя в последние десятилетия и в России, $и$ за рубежом появилось множество работ, посвященных интертексту и интертекстуальности в сфере художественного дискурса, проблему межтекстового взаимодействия нельзя считать исчерпанной»-так начинается известная монография Н. А. Фатеевой «Контрапункт интертекстуальности, или интертекст в мире текстов» [1, с. 4], увидевшая свет в 2000 г. С тех пор минуло двадцать лет, но приведенная фраза не потеряла своей актуальности. Действительно, до сих пор дискуссионным остается целый ряд ключевых вопросов теории интертекста: от определения объема понятия «интертекст» и выработки четких критериев, позволяющих констатировать наличие или отсутствие в изучаемом тексте инотекстового «заимствования», до построения обобщающей классификации интертекстовых единиц и создания стройной и общепринятой терминосистемы в этой сфере. Очевидно, что названные вопросы тесно взаимосвязаны между собой, поэтому, пытаясь дать ответ на один из них, исследователь часто «вынужден» отвечать (хотя бы частично) и на остальные. Именно так обстоит дело и в нашем случае: ниже мы представим свой вариант исчисляющей классификации интертекстовых единиц, при этом в той или иной мере нам придется затронуть и другие аспекты изучения и описания интертекста.

\section{Объем понятия «интертекстовая единица» и ее терминологические наименования}

Итак, давно замечено (см., например, [2; 3]), что корпус межтекстовых заимствований «многоэтажен»: к первому этажу относят языковые единицы различных типов (слова, словосочетания, предложения, сверхфразовые единства и т. д.), отсылающие к какому-либо тексту; на следующих этажах размещаются элементы плана содержания текста: сюжеты, мотивы, образы и т. д. Это, безусловно, важное противопостав- ление абсолютизируется рядом исследователей (см., например, [2] и др.), считающих, что к интертекстуальным единицам следует относить только элементы «первого этажа». Наряду с таким узким подходом к трактовке интересующих нас единиц существует и широкий подход, с позиций которого в состав интертекстовых единиц включается все вышеперечисленное многообразие межтекстовых заимствований.

Нам представляется, что ограничения, устанавливаемые сторонниками узкого подхода, являются во многом искусственными. Причем немалую роль здесь, как нам кажется, играет и используемая терминология. Приведем аргументацию, которую использует Ю. С. Степанов: «корпус межтекстовых заимствований многоярусен, “многоэтажен” и на уровне первого этажа уже имеет устоявшееся наименование - интертекст. Интертекст - это то, что можнно читать в прямом смысле этого слова. Следующие этажи уже вряд ли можно назвать “текстами”, поскольку они состоят из “нечитаемого”- понятий, образов, представлений, идей» [2, c. 35]. Иными словами, по мнению автора, интертекстовый элемент - это обязательно текст. Но текст - это не «бессодержательная форма»: когда мы изучаем процессы и результаты межтекстового взаимодействия, то имеем дело со связями, а последние могут быть выражены самыми разными способами, совсем не обязательно только такими единицами, которые можно в прямом смысле прочитать.

С нашей точки зрения, термины интертекст, интертекстема, инотекстема, «чужое слово» и подобные терминологические единицы подспудно могут подталкивать исследовательскую мысль к узкой трактовке соответствующих понятий. Поэтому более удачным был бы термин, который своей внутренней формой указывал бы на связь текстов, а не на вид ее реализации.

Прежде чем предложить соответствующий термин, отметим, что терминология, используемая ис- 
следователями межтекстовых взаимодействий, до сих пор не устоялась. К числу наиболее употребительных терминологических единиц относятся циитата, peминисценциия, аллюзия, интертекстема, инотекстема, чужое слово и др. При этом разные ученые используют их в своих работах в различных значениях (подробнее см., например, [4]). Как известно, для терминосистемы важнейшее значение имеет выбор термина-гиперонима. На эту роль интертекстологами были выдвинуты следующие термины-кандидаты: цүитата [5], реминисиенция [6; 7], чужое слово [8] и интертекстема [9]. Попытки придать такое значение терминам ц̧итата или реминисизенция нам представляется неудачными, поскольку внутренняя форма и многолетнее использование «привязывает» их к наименованию определенных разновидностей интертекстовых единиц. Более удачным можно признать предложение К. С. Сидоренко использовать в качестве обобщающего термин интертекстема. Но, как уже было отмечено, слабой стороной такого решения является внутренняя форма данной терминологической единицы.

С нашей точки зрения, предпочтительнее было бы использовать в качестве обобщающего наименования интертекстовых единиц термин коннектема (от англ. connect - соединять(ся), связывать(ся), ассоциироваться), который, с одной стороны, создан по продуктивной для лингвистической терминологии модели (морфема, фонема, лексема, семема и т. д.), а с другой стороны, своей внутренней форме передает идею связи. Коннектемами, по нашему мнению, являются любые элементы текста А или множества текстов В, а также целые тексты, которые были в том или ином виде заимствованы в текст С или множество текстов D.

В различных «принимающих» контекстах одна и та же коннектема может быть представлена в тех или иных своих разновидностях. Например, коннектема «на заре туманной юности», восходящая к стихотворению А. В. Кольцова «Разлука», используется в различных заимствующих текстах в следующих вариантах: «на заре туманной старости», «на закате туманной юности», «на закате туманной молодости», «на заре туманной...», «заря туманной юности» и ряде других. Такие разновидности мы предлагаем называть коннектами. Из вышесказанного следует, что соотношение в терминологической паре коннектема-коннект такое же, как в парах морфема-морф или фонема-фон: «основная единица и ее вариант».

\section{Исчисляющая классификация интертекстовых единиц}

Как известно, названные языковые единицы (фонемьl, морфемы и т. д.) представляют собой не просто некоторые наборы разновидностей, а парадигмы, определенным образом упорядоченные множества вариантов. Эти множества образуются в результате выполнения над основным представителем данной единицы определенного ряда операций.

Что же собой представляет коннектема как парадигма коннектов? Ответ на этот вопрос мы получим, если построим исчисляющую классификацию интертекстовых единиц. Для построения такой классификации необходимо определить необходимый и достаточный набор классификационных параметров, «комбинаторика значений которых исчерпывает все теоретические реализации изучаемой категории» $[10$, c. 45-46].

С нашей точки зрения, необходимой и достаточной является следующая триада параметров.

1. АТРИБУТИРОВАННОСТЬ/НЕАТРИБУТИPОВАННОСТЬ: наличие указания на автора/авторов и/или текст-источник/тексты-источники коннекта или отсутствие таких указаний.

С точки зрения атрибутированности/неатрибутированности возможны три основных типа употребления коннекта в принимающем тексте:

а) употребления с четкой атрибуцией, которая может быть развернутой (с указанием автора/авторов и текста-источника/текстов-источников, а возможно, еще и части, главы, раздела текста-донора) или краткой (с указанием только автора или только текста-источника). Такие употребления сопровождаются простым указанием (в скобках или без) на автора и/или текст-источник или специальными конструкциями, которые мы будем называть маркерами четкой атрибуции. Примерами этих маркеров могут служить следующие единицы:

- Хписал / говорил / считал / заметил / подметил (, чтоо);

- Как писал / говорил / считал / заметил / подметил $X$;

- Как / верно сказано / написано у X-а / в произведении $\mathrm{Y}$;

- По словам / по слову / по выражению / по мысли $X-a$;

- (Приведем / вспомним) слова / строчку / строки / фразу / выражение / афоризм / изречение X-a;

- Как говорил / считал/заметил/подметил герой / персонаж романа «У» / X-a;

- У Х-а есть мысль / выражение / фраза / изречение;

- У X-а где-то сказано / написано / отмечено / подмечено;

-Перефразируя / цүитируя / X-а и изельй ряд других;

б) употребления с размытой атрибуцией, которая представляет собой отсылку к определенному множеству авторов и/или множеству созданных ими текстов. Такие употребления сопровождаются специальными конструкциями, которые часто содержат слова с семантикой «наименования лица по роду 
деятельности или статусу» (писатель, художник, ученый, политик и т. д.). Эти конструкции мы будем называть маркерами размытой атрибуции. В качестве примеров таких маркеров приведем следующие единицы:

- как писал / говорил / считал / заметил классик русской литературы / (великий) писатель / поэт / драматург / художник / композитор / артист / философ / ученый;

- говоря словами классика русской литературь / (великого) писателя / поэта / драматурга / философа / ученого;

- вспомним фразу классика русской литературы / (великого) писателя / поэта / драматурга / философа / ученого и многие другие;

в) употребления без атрибуции, т. е. без каких-либо указаний на авторскую и текстовую принадлежность коннекта.

2. МАРКИРОВАННОСТЬ/НЕМАРКИРОВАН-

НОСТЬ: выделение коннекта с помощью определенного набора специальных средств или отсутствие такого выделения.

К стандартным средствам такого рода относятся кавычки, курсив, набор со втяжкой и т. д. Мы будем называть их маркерами «чужесловности». Такие маркеры обычно употребляются по отдельности, но могут использоваться совместно для более четкого выделения коннекта.

3.КАНОНИЧНОСТЬ/ТРАНСФОРМИРОВАН-

НОСТЬ: сохранение коннекта в том виде, в каком он представлен в тексте-источнике, или его (более или менее существенное) преобразование (типы таких трансформаций будут указаны ниже).

Перечисленные варианты употребления коннектов связаны с их реализацией в определенных текстовых позициях. Как известно, существуют различные варианты классификаций таких позиций (см., например, [11; 12, с. 28-38] и др.). С нашей точки зрения, для описания интертекстовых единиц существенное значение имеют три текстовые позиции с определенным количеством их разновидностей: эпиграф (ко всему тексту, к его части, к группе текстов), заглавие (всего текста, его части, группы текстов), тело текста (включая начало текста, конец текста, реплику персонажа и т. д.). Охарактеризуем каждую из них.

1. Позиция эпиграфа специально предназначена для размещения интертекстовых единиц. Поэтому неудивительно, что именно она является сильной позицией для коннектов, которые (кроме особых случаев) не подвергаются здесь ни одному типу трансформаций, т. е. сохраняют все характеристики текста-источника, снабжаются четкой атрибуцией и особым образом маркируются. Иными словами, именно в этой позиции коннектема реализуется в своем основном варианте - четко атрибутированном, маркированном и каноническом коннекте.

2. Позиция заглавия является важнейшей для текста или для его части, и потому появление здесь коннекта является показателем сильной межтекстовой связи. Однако с точки зрения интертекстовой парадигматики данная позиция сильной не является. В качестве заглавия могут использоваться как маркированные и канонические, так и немаркированные и трансформированные коннекты. Интертекстовые же единицы с четкой или хотя бы размытой атрибуцией и вовсе не могут здесь употребляться.

3. Позиция в «теле» текста с точки зрения интертекстовой парадигматики также является слабой. В данной позиции может употребляться любой тип коннекта.

Обобщим вышесказанное, представив результаты наших рассуждений в виде таблицы, наглядно демонстрирующей соотношение классификационных параметров и основных текстовых позиций:

\begin{tabular}{|l|c|c|c|}
\hline & $\begin{array}{c}\text { Атрибутиро- } \\
\text { ванность }\end{array}$ & $\begin{array}{c}\text { Маркирован- } \\
\text { ность }\end{array}$ & $\begin{array}{c}\text { Канонич- } \\
\text { ность }\end{array}$ \\
\hline Эпиграф & + & + & + \\
\hline Заглавие & - & $+/-$ & $+/-$ \\
\hline «Тело» текста & $+/-$ & $+/-$ & $+/-$ \\
\hline
\end{tabular}

Из вышесказанного следует, что важнейшими операциями, которые можно производить с коннектами, являются:

1) СНЯТИЕ АТРИБУЦИИ (ДЕАТРИБУЦИЯ). Если принять, как мы сделали это ранее, что основным вариантом коннектемы является четко атрибутированный коннект, тогда ясно, что снятие атрибуции может быть двух видов:

а) частичное, которое предполагает замену четкой атрибуции коннекта на размытую (см. выше);

б) полное, в результате которого коннект полностью лишается атрибуции;

2) СНЯТИЕ МАРКИРОВКИ (ДЕМАРКИРОВКА). Как уже было сказано, основный вариант коннектемы является маркированным, отмеченным одним или несколькими «маркерами чужесловности». Соответственно, демаркировка предполагает удаление этих маркеров и употребление коннекта без каких-либо формальных средств, указывающих на его «чужеродность» по отношению к данному тексту;

3) ТРАНСФОРМАЦИЯ. Преобразования, которым может подвергаться коннект, весьма разнообразны. Можно выделить следующие стандартные разновидности трансформаций интертекстовой единицы:

а) замена компонента/компонентов. Важно отметить, что замещаться может любой элемент коннекта: словосочетания, слова, знаки препинания и т. д.;

б) удаление компонента/компонентов (см. предыдущий пункт); 
в) добавление компонента/компонентов. Данная операция предполагает введение новых элементов, которые синтаксически связаны с другими элементами коннекта, а не просто разделяют интертекстовую единицу на несколько частей. Добавление компонентов не следует путать со следующей операцией;

г) дистантное расположение компонентов. Эта операция подразумевает механическое разделение исходного коннекта на несколько частей путем вставки между его элементами других элементов;

д) перестановка компонентов. Данная операция заключается в изменении порядка следования элементов в исходном коннекте;

е) морфологическая трансформация. Эта операция предполагает изменение одних форм, входящих в исходный коннект слов, на другие формы данных лексем;

ж) синтаксическая трансформация. Такая операция подразумевает изменение синтаксической структуры исходного коннекта.

При этом очевидно, что перечисленные операции могут производиться как отдельно друг от друга, так и совместно (накладываясь одна на другую).

Теперь у нас есть все необходимое для построения исчисляющей классификации интертекстовых единиц, которая может быть представлена в виде следующей таблицы:

\begin{tabular}{|c|c|c|}
\hline $\begin{array}{c}\text { Атрибути- } \\
\text { рованность }\end{array}$ & Маркированность & Каноничность \\
\hline+ & + & + \\
\hline+ & + & - \\
\hline+ & - & + \\
\hline+ & - & - \\
\hline- & + & + \\
\hline- & + & - \\
\hline- & - & + \\
\hline- & - & - \\
\hline
\end{tabular}

Данная таблица наглядно показывает, что парадигма интертекстовых единиц, составляющих коннектему, включает в себя восемь базовых типов коннектов:

1) атрибутированный, маркированный, канонический коннект;

2) атрибутированный, маркированный, трансформированный коннект;

3) атрибутированный, немаркированный, канонический коннект;

4) атрибутированный, немаркированный, трансформированный коннект;

5) неатрибутированный, маркированный, канонический коннект;

6) неатрибутированный, маркированный, трансформированный коннект;

7) неатрибутированный, немаркированный, канонический коннект;

8) неатрибутированный, немаркированный, трансформированный коннект.

Как уже было отмечено выше, существуют разные способы атрибуции, маркировки и трансформации исходного коннекта. Из этого следует, что большинство из восьми перечисленных типов коннектов делится на ряд подтипов, а те, в свою очередь, могут быть представлены в текстах десятками, сотнями и даже тысячами своих вариаций. Проиллюстрируем это утверждение, перечислив 8 базовых типов коннектов, составляющих коннектему «Раззудись, плечо! Размахнись, рука!» (из знаменитого «Косаря» А. В. Кольцова), и примеры их употребления (большая часть взята из [13, c. 109-114]):

\begin{tabular}{|l|l|}
\hline \multicolumn{1}{|c|}{ Тип коннекта } & \multicolumn{1}{|c|}{ Пример } \\
\hline $\begin{array}{l}\text { Атрибутированный (тип атрибуции - четкая), } \\
\text { маркированный (маркер - кавычки), канониче- } \\
\text { ский коннект }\end{array}$ & $\begin{array}{l}\text { Так и стоит над Воронежем Алексей Кольцов в кавалерийской шинели, } \\
\text { и невольно на ум приходят его знаменитые строчки: «Раззудись, плечо, } \\
\text { размахнись, рука!». } \\
\text { (А. М. Городницкий. «И жить еще надежде») }\end{array}$ \\
\hline $\begin{array}{l}\text { Атрибутированный (тип атрибуции - } \\
\text { размытая), маркированный, трансформирован- } \\
\text { ный коннект }\end{array}$ & $\begin{array}{l}\text { Автор. Да ни к чему писателю изображать из себя супермена или } \\
\text { культиста. } \\
\text { Редактор. Не могу тут принять вашу точку зрения. Кулаки молодцу не } \\
\text { помеха. Добро должно быть с кулаками. Сравните хоть с классикой: } \\
\text { «Раззудсь, плечо!». } \\
\text { (М. И. Веллер. Красная редактура) }\end{array}$ \\
\hline $\begin{array}{l}\text { Атрибутированный (тип атрибуции - четкая), } \\
\text { немаркированный, трансформированный (тип } \\
\text { преобразования - усечение) коннект }\end{array}$ & $\begin{array}{l}\text {-И кто смеет говорить о несвободе наших писателей? Да у меня, } \\
\text { когда я пишу, вольный размах кольцовского косаря, раззудись рука. } \\
\text { (А. И. Солженицын. Абрикосовое варенье) }\end{array}$ \\
\hline $\begin{array}{l}\text { Атрибутированный (тип атрибуции - } \\
\text { размытая), немаркированный, канонический } \\
\text { коннект }\end{array}$ & $\begin{array}{l}\text { Понравилась такая мысль Николаю: пойти с дедом на настоящий сенокос. } \\
\text { Даже зауважал себя - ведь был он, ко всему прочему, еще и начитан, в } \\
\text { школе, вместо уроков, всегда книжки читал. И потому знал из романов } \\
\text { Толстого, что косьба хоть и обильного пота требует, зато удовольствие и } \\
\text { удовлетворение приносит; да и классика-поэзия заманивает: раззудись, } \\
\text { плечо, размахнись, рука! } \\
\text { (Э. И. Алексеев. Дед) }\end{array}$ \\
\hline
\end{tabular}




\begin{tabular}{|c|c|}
\hline $\begin{array}{l}\text { Неатрибутированный, маркированный (маркер } \\
\text { - кавычки), канонический коннект }\end{array}$ & $\begin{array}{l}\text { Революцию старик Гиляровский встретил как крупнейшую газетную } \\
\text { сенсацию и разворот русского бунтарского духа. Он искал ее истоки в } \\
\text { разинщине, пугачевщине, в крестьянских бунтах и «красных петухах». } \\
\text { «Сарынь на кичку, ядреный лапоть», «Размахнись, рука, раззудись, пле- } \\
\text { чо!». (К. Г. Паустовский. Повесть о жизни. Начало неведомого века) }\end{array}$ \\
\hline $\begin{array}{l}\text { Неатрибутированный, маркированный (маркер } \\
\text { - кавычки), трансформированный (тип преоб- } \\
\text { разования - замена компонента) коннект }\end{array}$ & $\begin{array}{l}\text { В этих диких побиениях приходчины, совершаемых в потемках, } \\
\text { выражалась, с одной стороны, какая-то нелепая удаль «раззудись, плечо, } \\
\text { размахнись, кулак!». } \\
\text { (Н. Г. Помяловский. Очерки бурсы) }\end{array}$ \\
\hline $\begin{array}{l}\text { Неатрибутированный, немаркированный, } \\
\text { канонический коннект }\end{array}$ & $\begin{array}{l}\text { 5. Русские растоптали буржуазию-тараканьё, } \\
\text { а что ж англичане смотрят на неё! } \\
\text { 6. Раззудись плечо, } \\
\text { размахнись рука, } \\
\text { чтоб в воздухе летали буржуазные окорока! } \\
\text { (В. В. Маяковский. Братство) } \\
\end{array}$ \\
\hline $\begin{array}{l}\text { Неатрибутированный, немаркированный, } \\
\text { трансформированный (типы преобразований - } \\
\text { перестановка компонентов, замена компонента) } \\
\text { коннект }\end{array}$ & $\begin{array}{l}\text { - Рука, размахнись, } \\
\text { раззудись, душа! } \\
\text { Гуляй, } \\
\text { Правосудие наше! } \\
\text { (В. В. Маяковский. Гулом восстаний, на эхо положенным, об этом дадут } \\
\text { настоящий стих, а я лишь то, что сегодня можно, скажу о деле 26-ти) }\end{array}$ \\
\hline
\end{tabular}

\section{Заключение}

Для простоты и наглядности в качестве иллюстративного материала мы использовали интертекстовую единицу «первого яруса». Однако предложенная нами исчисляющая классификация коннектов позволяет описать и «предсказать» любой вариант употребления коннектем, относящихся и к другим «ярусам» межтекстовых заимствований, что открывает широкие возможности ее применения. Одной из таких возможностей может стать использование данной классификации для решения задачи автоматизации поиска интертекстовых единиц.

\section{ЛИТЕРАТУРА}

1. Фатеева Н. А. Контрапункт интертекстуальности, или Интертекст в мире текстов. М. : Агар, 2000. 280 с.

2. Степанов Ю. С. «Интертекст», «интернет», «интерсубъект» (к основаниям сравнительной концептологии) // Изв. РАН. Сер. лит. и яз. 2001. Т. 60, № 1. С. 3-11.

3. Москвин В. П. Интертекстуальность : Понятийный аппарат. Фигуры, жанры, стили. Изд. 3-е. M. : URSS, 2015. 168 c.

4. Кузьмина Н. А. Интертекст и его роль в процессах эволюции поэтического языка / науч. ред. Н. А. Купина. 2-е изд., стер. М. : Едиториал УРСС, 2004. 267 с.

5. Козицккая E. A. Смыслообразующая функция цитаты в поэтическом тексте : пособие по спецкурсу. Тверь : Твер. гос. ун-т, 1999. 140 с.

6. Супрун A. E. Текстовые реминисценции как языковое явление // Вопросы языкознания.1995. № 6. C. 17-29.

7. Сльишкин Г. Г. Лингвокультурные концепты прецедентных текстов. М. : Academia, 2000. 142 c.
8. Волошинов В. Н. Философия и социология гуманитарных наук. СПб. : Аста-пресс ltd, 1995. 388 с.

9. Сидоренко К. П. Цитаты из «Евгения Онегина» А. С. Пушкина в текстах разного жанра. СПб. : Образование, 1998. 316 c.

10. Храковский В. С. Исчисляющие классификации в типологии // Вопросы языкознания. 1996. № 3. С. $42-$ 54.

11. Арнольд И. В. Стилистика. Современный английский язык. М., 2006. 384 с.

12. Кольцова Л. М. Пунктуация художественного текста : теория, практика, интерпретация. Воронеж : НАУКА-ЮНИПРЕСС, 2012. 228 с.

13. Кольцьова Л. М., Чуриков С. А. Крылатое слово А. В. Кольцова. Опыт словаря. 2-е изд., испр. и доп. Воронеж : ИПЦ ВГУ, 2012. 182 с.

\section{REFERENCES}

1. Fateeva N. A. Kontrapunkt intertekstual'nosti, ili Intertekst $v$ mire tekstov [Counterpoint of intertextuality, or Intertext in the world of texts ]. Moscow: Agar, 2000. 280 p.

2. Stepanov Y. S. «Intertekst», «internet», «intersubekt» (k osnovanijam sravnitel'noj konceptologii) [«Intertext», «Internet», «intersubject» (to the foundations of comparative conceptology)]. In Izvestija RAN. Ser. lit. i jaz. 2001. Vol. 60, No. 1. Pp. 3-11.

3. Moskvin V. P. Intertekstual'nost': Ponjatijnyj apparat. Figury, zhanry, stili. [Intertextuality: Conceptual apparatus. Shapes, genres, and styles]. 3rd ed. Moscow: URSS, 2015. 168 p.

4. Kuz'mina N. A. Intertekst $i$ ego rol'v processah jevoljucii pojeticheskogo jazyka [Intertext and its role in the processes of evolution of the poetic language]. 2rd ed. Moscow: Editorial URSS, 2004. 267 p. 
5. Kozickaja E. A. Smysloobrazujushhaja funkcija citaty $v$ pojeticheskom tekste [The function meaning creation of a quotation in a poetic text]. Tver', 1999. 140 p.

6. Suprun A. E. Tekstovye reminiscencii kak jazykovoe javlenie [Textual reminiscences as a linguistic phenomenon]. In: Voprosy jazykoznanija. 1995. No. 6. Pp. 17-29.

7. Slyshkin G. G. Lingvokul'turnye koncepty precedentnyh tekstov [Linguocultural concepts of precedent texts]. Moscow: Academia, 2000. 142 p.

8. Voloshinov V. N. Filosofija i sociologija gumanitarnyh nauk [Philosophy and sociology of the Humanities]. Saint Petersburg: Asta-press 1td, 1995. 388 p.

9. Sidorenko K. P. Citaty iz «Evgenija Onegina» A. S. Pushkina v tekstah raznogo zhanra [Quotes from «Eugene

Воронежский государственный университет

Чуриков С. А., кандидат филологических наук, доиент кафедры русского языка

E-mail: churikovsa@yandex.ru

Поступила в редакциию 3 июля 2020 г.

Принята к публикаџии 25 сентября 2020 2.

\section{Для цичтирования:}

Чуриков С. А. Опыт построения исчисляющей классификации интертекстовых единиц // Вестник Воронежского государственного университета. Серия: Лингвистика и межкультурная коммуникация. 2020. № 4. C. 6-12. DOI: https://doi.org/10.17308/lic.2020.4/3073
Onegin» by A. S. Pushkin in texts of different genres]. Saint Petersburg: Obrazovanie, 1998. 316 p.

10. Hrakovskij V. S. Ischisljajushhie klassifikacii v tipologii [Enumarerative classifications in typology]. In: Voprosy jazykoznanija. 1996. No. 3. Pp. 42-54.

11. Arnol'd I. V. Stilistika. Sovremennyj anglijskij jazyk [Stylistics. Modern English]. Moscow, 2006. 384 p.

12. Kol'cova L. M. Punktuacija hudozhestvennogo teksta: teorija, praktika, interpretacija [Punctuation of artistic text: theory, practice, interpretation]. Voronezh: NAUKA-JUNIPRESS, 2012. 228 p.

13. Kol'cova L. M., Churikov S. A. Krylatoe slovo A. V. Kol'cova. Opyt slovarja [Flying word of A. V. Koltsov. An attempt at creating the dictionary]. 2nd ed. Voronezh: IPC VGU, 2012. 182 p.

Voronezh State University

Churikov S. A., Candidate of Philology, Associate Professor of the Russian Language Department

E-mail: churikovsa@yandex.ru

Received: 3 July 2020

Accepted: 25 September 2020

\section{For citation:}

Churikov S. A. An attempt at constructing an enumerative classification of intertextual units. Proceedings of Voronezh State University. Series: Linguistics and Intercultural Communication. 2020. No. 4. Pp. 6-12. DOI: https://doi. org/10.17308/lic.2020.4/3073 